International Journal of HRD Practice, Policy and Research 2018, Vol 3 No 1: 91-93

doi: 10.22324/ijhrdppr.3.106

HRD Forum —Viewpoint

\title{
Quality Matters in Apprenticeships
}

\author{
Ann McSorley, Scottish Social Services Council
}

\section{Introduction}

This viewpoint seeks to generate practice informed discussion on the characteristics and quality issues of a positive apprenticeship experience. The article suggests how work based research is informing practice in the use of apprenticeships in social services and contributes to understanding some of the factors that influence the learning process. It argues that further studies are required which evaluate the quality of experiences and characteristics of good practice in apprenticeships as the model of vocational learning is expanded further.

\section{Context}

Apprenticeships are an evolving tradition, perceived as a model of acquiring a particular skill, trade or craft to support individuals move from the periphery of practice, as a novice, towards becoming an experienced worker. In the context of renewed international attention apprenticeships have emerged as a key policy tool deployed by national governments to increase workforce skills and sustain economic growth. There are differences in the routes of apprenticeships amongst devolved nations in the United Kingdom, particularly the standards on which they are based. Whilst apprenticeships are available to all ages, young people have been the particular focus of UK government policy to address the needs of those without employment or training. Other nations have developed similar models as a means to address unemployment and increase economic competitiveness.

The characteristics of a Modern Apprenticeship are that the individual is in paid employment and studying for a national qualification at the same time. In Scotland the expansion into Foundation Apprentice frameworks for those in the senior phase at school, and development of degree level Graduate Apprenticeships, has further established apprenticeships as an important route for individuals to access work based learning situated within national qualification structures. This has increased opportunities for apprenticeships gaining parity with other academic learning routes.

The expansion in the range of apprenticeships and increase in numbers of apprentices has required further consideration on how the desire to expand the model is balanced with the quality of learning and experience gained. As the modern apprenticeship model has progressed the attention of national agencies (OECD, 2016) has become focused on establishing a method of evaluation. Such methods consider a wide range of quantitative data but perceptions of apprenticeships may be strengthened through qualitative data focused on how learning is supported. In studies carried 
out in my area of practice within social services there are quality themes that have emerged that merit further consideration (McSorley, 2016). These quality themes include activities deployed to support learning and the role of the mentor. Using findings from practice I explore these quality themes further below.

\section{Quality Themes}

Work based learning as a means of socially situated learning within a community of practice has particular relevance to modern apprenticeships. It recognizes the interaction of a community within a sector of employment, or workplace, who demonstrate competence within a given field through sharing information and learning. Worthen and Berchman (2010) suggest that there is limited information in the literature on how apprentices learn in the workplace and it is an area that would merit further investigation.

A possible framework for evaluation which describes the activities supporting learning is the 'cognitive apprentice approach' (Dennen \& Burner, 2007). In apprenticeships it is argued that work drives learning which may result in gaps in knowledge if situations are not encountered. In the cognitive apprenticeship approach the links between work-based and academic learning are made more explicit. Strategies deployed in cognitive apprenticeships include the following:

- Modelling (demonstration of practice).

- Explanation (explaining why practice is carried out in such a way).

- Coaching (monitor apprentice whilst they carry out practice).

- Scaffolding (gradually reduce support to assist independent action).

- Reflection (apprentice assesses and analyses their learning and practice).

- Articulation (reflection is expressed in verbal or written form).

- Exploration (apprentice is encouraged to consider applicability of learning).

Study carried out with learning providers in the Scottish social service sector has established that a range of methods and approaches are used which reflect those identified in the cognitive apprenticeship model. The study described activity as being customized to meet individual learning and practice needs (Scottish Social Services Council, 2016). The findings of the study suggest that the process may be made more explicit as a learning curriculum.

Additional practice based research has taken place on the characteristics of what makes a positive apprenticeship experience. Initial findings indicate the importance of the relationship between the apprentice and their mentor. As the apprentice moves from being a novice to achievement of full participation in their field of practice the relationship with mentor and other colleagues is crucial as it supports integration of what they have learnt with the development of a professional identity. Access to a mentor and support of the workplace community can contribute to a positive learning experience for all parties. This is due to the reciprocal nature of learning between apprentice and mentor as the approaches and experiences the apprentice brings to the workplace contribute to co-production and reproduction of workplace culture. Therefore evaluation of this aspect of the apprenticeship is another indicator of quality of experience and has been considered in recent consultations on defining an apprenticeship (Scottish Apprenticeship Advisory Board, 2017). 


\section{Conclusion}

Apprenticeships offer many people opportunities to engage with a desired occupation and learn in a supportive and enabling community of practice. This viewpoint has sought to use findings from practice informed research to set out some quality themes which may contribute to the debate on apprenticeships. This may assist towards addressing the tension of maintaining quality of experience at a time of expansion of the model.

Studies of practice are helpful in exploring challenges experienced in practice and the approaches which may be used to enhance learning and evaluate the apprentice experience. This viewpoint has identified some approaches and interventions used within apprenticeships which may benefit from being included within evaluation. As a consequence it supports a framework for evaluation which keeps the quality of experience at the heart of the learning process.

\section{References}

Dennen, V. P., \& Burner, K. J. (2007). The Cognitive Apprenticeship Model in Educational Practice. Handbook of research on educational communications and technology, 425-439. Available http:// www.aect.org/edtech/edition3/ER5849x_C034.fm.pdf [Accessed June 2016]

McSorley, A. (2016). A Study of Pedagogical Practice and Identity Development in Modern Apprenticeships (Masters Dissertation)

OECD (2016). Evaluation Framework for Modern Apprenticeships in Scotland. OECD Science, Technology and Innovation Policy Papers, 35.

Scottish Apprenticeship Advisory Board (2017). Defining an Apprenticeship. https://www. skillsdevelopmentscotland.co.uk/media/43954/defining-an-apprenticeship-consultation-questions.pdf [Accessed March 2018]

Scottish Social Services Council (2016). Knowledge Acquisition http://www.sssc.uk.com/about-the-sssc/ multimedia-library/publications?task=document.viewdoc\&id=3202 [Accessed January 2018]

Worthen, H., \& Berchman, M. (2010). Apprenticeships: What happens in On-the-Job Training (OJT)? In Billett, S. (ed.) Learning Through Practice. Models, Traditions, Orientations and Approaches. London: Springer.

\section{The Author}

Ann works as a Learning and Development manager in the Scottish Social Services Council with particular responsibility for vocational qualifications and standards. The Scottish Social Services Council registers the social services workforce in Scotland and regulates their training and learning. She is particularly interested in the acquisition and application of knowledge in practice and the development of professional identity. 